\title{
Epidemiology of Burnout and Its Association with Academic Performance Among Medical Students at Hail University, Saudi Arabia
}

"Ahmed H. Aljadani, ${ }^{1}$ Ahmed Alsolami, ${ }^{1}$ Samiah Almehmadi, ${ }^{2}$ Ahmed Alhuwaydi, ${ }^{3}$ Anas Fathuldeen ${ }^{4}$

\begin{abstract}
Objectives: Burnout syndrome is a condition that is well-documented globally among medical students and affects their academic performance due to high levels of associated stress and psychiatric morbidities. This study aimed to assess burnout prevalence and predictors along with its association with academic performance among medical students at Hail University, Saudi Arabia. Methods: A questionnaire-based cross-sectional survey of medical students was conducted between May and June 2019 at the Medical College at Hail University. The English version of the Maslach Burnout Inventory (MBI)-Student Survey was used to assess the three components of burnout syndromecynicism, emotional exhaustion and professional efficacy. A fixed-model multivariate logistic regression analysis was conducted for each of the three MBI components' levels and for total burnout to identify factors significantly associated with burnout syndrome. Results: A total of 218 students were included in this study (response rate: $53.8 \%$ ). The majority of participants were female $(\mathrm{n}=121 ; 55.5 \%)$ medical students ranging between $21-24$ years of age. High emotional exhaustion, high cynicism and low professional efficacy was found among 79.4\%, $61.0 \%$, and 37.6\%, respectively, of respondents. The overall prevalence of high burnout was $27.1 \%(n=59)$. Female students were at almost double the risk for high emotional exhaustion compared to male students (adjusted odds ratio $[\mathrm{AOR}]=2.14,95 \%$ confidence interval $[\mathrm{CI}]: 1.06-4.34 ; P=0.034)$. Students with grade point averages (GPA; on a four-point scale) ranging between 3.51-4.0 were considerably less prone ( $83 \%$ less risk) to experience burnout as compared to students with a GPA $\leq 2.0$ (AOR = 0.17, 95\% CI $=0.03-0.91, P=0.039$ ). Conclusion: High levels of overall burnout were reported among Hail University medical students. Students with a higher GPA, however, were found to be less prone to burnout.
\end{abstract}

Keywords: Burnout Syndrome; Medical Students; Fatigue; Stress; Saudi Arabia.

\section{Advances in KNOWLedge}

The current study found that undergraduate medical students studying at Hail university in Saudi Arabia demonstrated high levels of burnout.

The current study shows a higher risk of emotional exhaustion among female students compared to male students.

\section{Application of Patient Care}

Adoption of preventive measures and early detection of burnout syndrome are an important steps in mental health promotion for medical students especially those with low academic performance rate.

$\mathrm{T}$ HE TERM BURNOUT SYNDROME WAS introduced in the late 1960s to describe the emotional or physiological stress and depersonalisation experienced by health practitioners. ${ }^{1}$ Over the years, it has been used more widely to acknowledge any job-related stress including depressive symptoms in medical practice. ${ }^{2}$ Burnout syndrome is characterised by impaired personal accomplishments and is often induced by repeated workplace stressors. ${ }^{3}$

Burnout syndrome affects medical students as well as experienced physicians and generally has three dimensions: cynicism, emotional exhaustion and low professional efficacy. Cynicism refers to a student's mental distance from lessons; exhaustion refers to severe fatigue and emotional depletion due to academic demands; and professional efficacy refers to a student's self-perception as academically accomplished or incompetent. ${ }^{4}$
Medical education is recognised for being long and emotionally exhausting. Several studies have reported burnout rates among medical students ranging from $10.3-76.8 \%$, with variable assessment methodologies. ${ }^{5-12}$ Medical students often have a disproportionately work-focused work-life balance that affects their time for family, friends or leisure, leading to high levels of stress, anxiety and other psychiatric morbidities. ${ }^{13}$

A 2008 study from the USA demonstrated that approximately $50 \%$ of students had burnout syndrome and $10 \%$ experienced suicidal ideation during their study period. ${ }^{8}$ In a survey conducted in Saudi Arabia, severe depressive symptoms were reported in $11 \%$ and 71.9\% of medical students at King Saud University and Jazan University, respectively. ${ }^{10}$ Ibrahim et al. conducted a study about anxiety and depression 
among female medical students at King Abdul Aziz University, Jeddah, Saudi Arabia, and found depression and morbid anxiety occurred in $34.9 \%$ and $14.7 \%$, respectively. ${ }^{14}$ In a systematic review and metaanalysis, Frajerman et al. uncovered a vast amount of literature on burnout syndrome among medical students. ${ }^{15}$

Burnout syndrome has unfavourable effects on students' performance; thus, preventive steps are required. Although some medical schools have introduced mental health programmes to support students in their medical training period, most institutions have yet to address this issue. Moreover, further studies are required to investigate burnout's impact on academic performance for those students. Therefore, this study aimed to measure the prevalence and predictors of burnout among medical students at Hail University, Saudi Arabia, with a focus on its association with academic performance. The results of this study can help guide educational authorities to build more robust preventive strategies to enhance mental health among medical students during their training period.

\section{Methods}

This cross-sectional study was conducted from May to June 2019 among medical students in Hail Medical College, Hail University. Medical students in Saudi Arabia spend two years in pre-clinical and three years in clinical training. Hail University Medical College enrolled 405 students in the year 2018/2019 of which most were male $(n=203)$. During the study period, male-to-female distribution was almost equal for all five levels at the college, with approximately 80 students per academic level. No specific exclusion criteria were used in this study. Data were collected using an online form distributed to students via their official university e-mail addresses. Individuals were contacted twice during the study in order to increase the number of responses.

The English version of the Maslach Burnout Inventory-Student Survey (MBI-SS), a modified version of the Maslach Burnout Inventory-General Survey, is a self-administered questionnaire and was used to assess burnout prevalence among the participants. It has been validated and has demonstrated adequate reliability among students from Portugal, Spain, the Netherlands and China. ${ }^{16,17}$ However, this tool has yet to be validated in Saudi Arabia.

The first section of the questionnaire captured students' socio-demographic characteristics including age, gender, marital status, academic level and most recent grade point average (GPA). The second section consisted of 15 MBI-SS questions focusing on the triad of exhaustion (five items), cynicism (four items) and professional efficacy (six items). All items were assessed by a seven-point Likert scale ranging from six (always) to zero (never). The total scores in each of the three domains were categorised into high, moderate or low scores. The scores for the MBI-SS survey were divided into three domains: professional efficacy (low $\leq 22$; moderate $=23-27$; high $\geq 28$ ), emotional exhaustion (low $=0-9$; moderate $=10-14$; high $>14$ ) and cynicism (low $=0-1$; moderate $=2-6$; high $>6$ ). High scores for cynicism and emotional exhaustion with low scores for academic efficacy indicated a high level of burnout.

Data analysis was conducted using Statistical Package for the Social Sciences (SPSS), Version 25 (IBM, Corp., Armonk, New York, USA). All categorical variables were presented as numbers and percentages. Fisher's exact and Chi-squared tests were used interchangeably; these tests helped determine significant associations between categorical variables. Fisher`s exact test was used in cases with lower than expected frequencies (i.e. $<5$ in one or more cells). Otherwise, the Chi-squared test was used. A fixed model multivariate logistic regression analysis was conducted for each of the three MBI component levels and total burnout to identify factors significantly associated with burnout syndrome. Using RaoSoft ${ }^{\circledR}$ (Raosoft, Inc., Seattle, Washington, USA), an online calculator, the minimum effective sample size was calculated to ensure the number of respondents required to justify the study's findings were approached. The minimum required sample was 198 when calculated with a 95\% confidence interval (CI), 5\% margin of error, total number of students of 405 and prevalence of burnout of $50 \%$. Adjusted odds ratio (AOR) and $95 \% \mathrm{CI}$ were also calculated. A $P$ value $<0.05$ was considered statistically significant.

Ethical approval from the Institutional Review Board at Hail University Medical College was obtained (HREC 00061/CM-UOH.12/19). Information about the study's purpose appeared on the first page in the electronic survey indicating that students' participation was voluntary. Respondents' identities were not collected so personal information could not be matched to individual responses.

\section{Results}

A total of 218 medical students participated in this study (response rate: $53.8 \%$ ) of which the majority were female $(\mathrm{n}=121 ; 55.5 \%)$ and were $21-24$ years old $(\mathrm{n}=175 ; 80.3 \%)$. Most respondents $(\mathrm{n}=208$; 95.4\%) indicated that they were single. Most students achieved a GPA of $\geq 3.01$ ( $n=154 ; 70.6 \%$ ) of which 
Table 1: Factors associated with high burnout and burnout components among medical students at Hail University, Saudi Arabia, in $2019(\mathrm{~N}=218)$

\begin{tabular}{|c|c|c|c|c|}
\hline \multirow[t]{2}{*}{ Characteristic } & \multicolumn{4}{|c|}{ n (\%) } \\
\hline & $\begin{array}{l}\text { High emotional } \\
\text { exhaustion }\end{array}$ & High cynicism & $\begin{array}{l}\text { Low professional } \\
\text { efficacy }\end{array}$ & High burnout \\
\hline \multicolumn{5}{|l|}{ Age in years } \\
\hline $17-20(\mathrm{n}=33)$ & $25(75.8)$ & $19(57.6)$ & $7(21.2)$ & 4. (12.1) \\
\hline $21-24(\mathrm{n}=175)$ & $142(81.1)$ & $109(62.3)$ & $71(40.6)$ & $53(30.3)$ \\
\hline$>24 .(\mathrm{n}=10)$ & $6(60.0)$ & $5(50.0)$ & $4 .(40.0)$ & $2(20.0)$ \\
\hline$P$ value & 0.240 & 0.853 & 0.171 & 0.086 \\
\hline \multicolumn{5}{|l|}{ Gender } \\
\hline Male $(\mathrm{n}=97)$ & $71(73.2)$ & $58(59.8)$ & $36(37.1)$ & $27(27.8)$ \\
\hline Female $(\mathrm{n}=121)$ & $102(84.3)$ & $75(62.0)$ & $46(38.0)$ & $32(26.5)$ \\
\hline$P$ value & 0.130 & 0.766 & 0.983 & 0.819 \\
\hline \multicolumn{5}{|l|}{ Marital status } \\
\hline Single $(\mathrm{n}=208)$ & $165(79.3)$ & $128(61.5)$ & $78(37.5)$ & $56(26.9)$ \\
\hline Married ( $\mathrm{n}=10)$ & $8(80.0)$ & $5(50.0)$ & $4(40.0)$ & $3(30.0)$ \\
\hline$P$ value & 0.998 & 0.222 & 0.840 & 0.538 \\
\hline \multicolumn{5}{|l|}{ Academic level } \\
\hline Second year $(n=42)$ & $31(73.8)$ & $25(59.5)$ & $9(21.4)$ & $5(11.9)$ \\
\hline Third year $(n=43)$ & $33(76.7)$ & $23(53.5)$ & $19(44.2)$ & $11(25.6)$ \\
\hline Fourth year $(\mathrm{n}=50)$ & $41(82.0)$ & $35(70.0)$ & $24(48.0)$ & $20(40.0)$ \\
\hline Fifth year $(n=43)$ & $36(83.7)$ & $26(60.5)$ & $15(34.9)$ & $13(30.2)$ \\
\hline Sixth year $(n=40)$ & $32(80.0)$ & $24(60.0)$ & $15(37.5)$ & $10(25.0)$ \\
\hline$P$ value & 0.211 & 0.879 & 0.086 & 0.050 \\
\hline \multicolumn{5}{|l|}{ GPA } \\
\hline$\leq 2.00(\mathrm{n}=7)$ & $6(85.7)$ & $5(71.4)$ & $4 .(57.1)$ & $3(42.9)$ \\
\hline $2.01-2.50(\mathrm{n}=15)$ & $13(86.7)$ & $12(80.0)$ & $8(53.3)$ & $7(46.7)$ \\
\hline $2.51-3.00(\mathrm{n}=42)$ & 33 (78.6) & $30(71.4)$ & $21(50.0)$ & $18(42.9)$ \\
\hline $3.01-3.50(\mathrm{n}=58)$ & $53(91.4)$ & $42(72.4)$ & $27(46.6)$ & $22(37.9)$ \\
\hline $3.51-4.00(\mathrm{n}=96)$ & $68(70.8)$ & $44(45.8)$ & $22(22.9)$ & $9(9.4)$ \\
\hline$P$ value & 0.134 & 0.009 & 0.001 & $<0.001$ \\
\hline
\end{tabular}

GPA = grade point average.

96 students (44.0\%) indicated maintaining a GPA between 3.51-4.00.

The parameters of burnout syndrome such as high emotional exhaustion, high cynicism and low professional efficacy had a prevalence of $79.4 \%(\mathrm{n}=173)$, $61.0 \%(\mathrm{n}=133)$ and $37.6 \%(\mathrm{n}=82)$, respectively [Figure 1 ].

The overall prevalence of high burnout was $27.1 \%$ $(\mathrm{n}=59)$. High burnout was reported among $40 \%$ ( $\mathrm{n}=20$ ) of students in their fourth year compared to $11.9 \%(n=5)$ of students in their second year of medical school. The overall association between high burnout and academic level was significant $(P=0.050)$. The

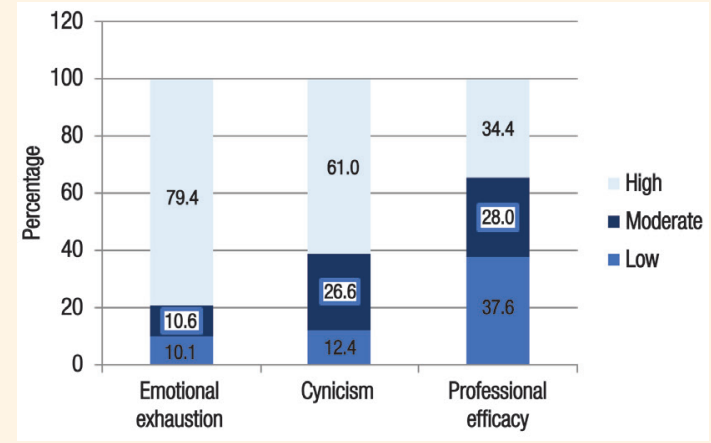

Figure 1: Frequency of components of burnout among medical students at Hail University, Saudi Arabia, in 2019. 
Table 2: Predictors of burnout among medical students based on results of multivariate logistic regression analysis $(\mathrm{N}=218)$

\begin{tabular}{|c|c|c|c|c|c|c|c|c|c|c|c|c|}
\hline & \multicolumn{3}{|c|}{ High emotional exhaustion } & \multicolumn{3}{|c|}{ High cynicism } & \multicolumn{3}{|c|}{ Low professional efficacy } & \multicolumn{3}{|c|}{ High burnout } \\
\hline & AOR & $95 \% \mathrm{CI}$ & $\begin{array}{c}P \\
\text { value }\end{array}$ & AOR & $95 \% \mathrm{CI}$ & $\begin{array}{c}P \\
\text { value }\end{array}$ & AOR & $95 \% \mathrm{CI}$ & $\begin{array}{c}P \\
\text { value }\end{array}$ & AOR & $95 \% \mathrm{CI}$ & $\begin{array}{c}P \\
\text { value }\end{array}$ \\
\hline \multicolumn{13}{|c|}{ Age in years } \\
\hline $17-20^{*}$ & 1.0 & & & 1.0 & & & 1.0 & & & 1.0 & & \\
\hline $21-24$ & 0.74 & $0.21-2.63$ & 0.644 & 0.90 & $0.30-2.63$ & 0.840 & 1.38 & $0.42-4.58$ & 0.596 & 1.05 & $0.23-4.79$ & 0.945 \\
\hline$>24$ & 0.12 & $0.01-1.16$ & 0.067 & 0.50 & $0.07-3.67$ & 0.496 & 1.39 & $0.18-10.8$ & 0.754 & 0.46 & $0.03-6.09$ & 0.555 \\
\hline \multicolumn{13}{|l|}{ Gender } \\
\hline Male* & 1.0 & & & 1.0 & & & 1.0 & & & 1.0 & & \\
\hline Female & 2.14 & $1.06-4.34$ & 0.034 & 1.21 & $0.67-2.17$ & 0.525 & 1.15 & $0.64-2.07$ & 0.649 & 1.10 & $0.57-2.13$ & 0.781 \\
\hline \multicolumn{13}{|c|}{ Marital status } \\
\hline Single* & 1.0 & & & 1.0 & & & 1.0 & & & 1.0 & & \\
\hline Married & 2.38 & $0.28-20.31$ & 0.428 & 0.65 & $0.14-2.99$ & 0.578 & 0.90 & $0.19-4.26$ & 0.891 & 1.37 & $0.24-7.78$ & 0.724 \\
\hline \multicolumn{13}{|c|}{ Academic level } \\
\hline $\begin{array}{l}\text { Second } \\
\text { year** }\end{array}$ & 1.0 & & & 1.0 & & & 1.0 & & & 1.0 & & \\
\hline $\begin{array}{l}\text { Third } \\
\text { year }\end{array}$ & 1.30 & $0.38-4.51$ & 0.677 & 0.65 & $0.22-1.87$ & 0.424 & 2.09 & $0.67-6.51$ & 0.204 & 1.83 & $0.44-7.61$ & 0.408 \\
\hline $\begin{array}{l}\text { Fourth } \\
\text { year }\end{array}$ & 1.66 & $0.43-6.38$ & 0.459 & 1.10 & $0.35-3.47$ & 0.873 & 1.94 & $0.59-6.40$ & 0.275 & 2.78 & $0.65-11.9$ & 0.168 \\
\hline $\begin{array}{l}\text { Fifth } \\
\text { year }\end{array}$ & 1.90 & $0.48-7.59$ & 0.363 & 0.75 & $0.23-2.37$ & 0.618 & 1.15 & $0.34-3.93$ & 0.821 & 1.86 & $0.42-8.29$ & 0.415 \\
\hline $\begin{array}{l}\text { Sixth } \\
\text { year }\end{array}$ & 2.10 & $0.48-9.24$ & 0.325 & 0.85 & $0.25-2.93$ & 0.800 & 1.30 & $0.36-4.77$ & 0.688 & 1.57 & $0.32-7.74$ & 0.577 \\
\hline \multicolumn{13}{|l|}{ GPA } \\
\hline$\leq 2^{*}$ & 1.0 & & & 1.0 & & & 1.0 & & & 1.0 & & \\
\hline $\begin{array}{l}2.01- \\
2.50\end{array}$ & 1.31 & $0.09-19.0$ & 0.844 & 1.80 & $0.21-15.4$ & 0.591 & 1.08 & $0.17-6.99$ & 0.938 & 1.50 & $0.23-9.90$ & 0.672 \\
\hline $\begin{array}{l}2.51- \\
3.00\end{array}$ & 0.67 & $0.07-6.45$ & 0.730 & 1.02 & $0.17-6.12$ & 0.985 & 0.85 & $0.16-4.38$ & 0.846 & 1.02 & $0.20-5.27$ & 0.981 \\
\hline $\begin{array}{l}3.01- \\
3.50\end{array}$ & 2.01 & $0.19-20.9$ & 0.558 & 0.99 & $0.17-5.82$ & 0.998 & 0.83 & $0.16-4.20$ & 0.823 & 0.92 & $0.18-4.71$ & 0.923 \\
\hline $\begin{array}{l}3.51- \\
4.00\end{array}$ & 0.43 & $0.05-3.88$ & 0.453 & 0.31 & $0.06-1.73$ & 0.183 & 0.29 & $0.06-1.45$ & 0.132 & 0.17 & $0.03-0.91$ & 0.039 \\
\hline
\end{tabular}

$A O R=$ adjusted odds ratio; $C I=$ confidence interval; $G P A=$ grade point average.

"Reference category.

highest rate of cynicism was observed among students whose GPAs ranged between 2.01-2.50, while the lowest rate was observed among those whose GPAs ranged between $3.51-4.00$ (80.0\% versus $45.8 \%$; $\mathrm{P}=$ 0.009). The highest rate of low professional efficacy was observed among students whose GPAs were $\leq 2.0$ while the lowest rate was observed among those whose GPAs ranged between 3.51-4.00 (57.1\% versus $22.9 \% ; P=0.001$ ). Regarding burnout, the highest rate was observed among students whose GPAs ranged between 2.01-2.50, while the lowest rate was observed among those whose GPA ranged between 3.51-4.00 (46.7\% versus $9.4 \% ; P<0.001$ ) [Table 1 ].

The multivariate logistic regression analysis revealed that female students were at almost double the risk for high emotional exhaustion compared to male students $(\mathrm{AOR}=2.14,95 \% \mathrm{CI}=1.06-4.34 ; P=0.034)$. Students with GPAs ranging from 3.51-4.00 (44\%) were considerably less prone to burnout compared to students with GPAs $\leq 2.0$ (AOR $=0.17,95 \% \mathrm{CI}=0.03-0.91$; $P=0.039$ ). Other associations with high burnout and burnout components were not statistically significant. [Table 2]. 


\section{Discussion}

The present study discovered a high prevalence of burnout syndrome among medical students at Hail University's Medical College. The results show alarming numbers that suggest that Saudi medical students may experience high burnout levels. Medical students are vulnerable to burnout as a result of high exposure to psychosocial stressors throughout their academic and training periods. ${ }^{18}$

Different rates of burnout have been reported in different countries and even within the same country. The prevalence of high emotional exhaustion, high cynicism and low professional efficacy in the current study was found to occur in $79.4 \%, 61.0 \%$, and $37.6 \%$ of respondents, respectively. The overall prevalence of high burnout was $27.1 \%$. In a recent study carried out in Riyadh, Saudi Arabia, a very high burnout prevalence of $67.1 \%$ was reported. ${ }^{4}$ In another study carried out in Riyadh, the prevalence of high emotional exhaustion, high depersonalisation and low personal accomplishment was 17.4\%, 56.9\% and 14.9\%, respectively, with an overall prevalence of burnout of $13.4 \%{ }^{19}$ The findings of the current study occur within the 13.4-67.1\% range previously discovered in Saudi Arabian medical schools.

The wide variation in reported rates of burnout in these studies, including the present one, could be attributed to the use of different instruments and scales in defining burnout. These instruments include the Copenhagen Burnout Inventory, Oldenburg Burnout Inventory, Modified Maslach Burnout Inventory, Short Perceived Stress Scale, Emotional Exhaustion Subscale of the Maslach Burnout Inventory and the English version of the MBI-SS. This variation could also be attributed to the cultural, social and environmental determinants of burnout in different situations. Further studies are required to ascertain the cause for burnout's wide-ranging prevalence among medical students.

The high level of competition among medical students in Saudi Arabia to pursue desirable postgraduate residency programmes may also contribute to the high level of burnout reported in this study. During their training and in order to maximise their chances for securing positions at the desired residency programmes, medical students must build a strong curriculum vitae which includes published research, presentations at conferences and academic activities. ${ }^{4}$ This rigor contributes to burnout among medical students.

Careful analysis of other studies carried out inside and outside Saudi Arabia have revealed no association between students' gender and burnout. ${ }^{4,20}$ In contrast, the current study shows a higher risk of high emotional exhaustion among female students when compared to their male peers. A recent Chinese systematic review similarly reported gender as a significant determinant of burnout. ${ }^{21}$

The current study showed a higher rate of burnout in students in their clinical years compared to those in preclinical years. This same finding was observed in a study carried out in Spain where the risk for burnout was significantly higher $(P<0.0001)$ among sixth-year students (37.5\%) compared to third-year students (14.8\%). ${ }^{20}$ However, Almalki et al. reported that academic year was not a predictor for burnout. ${ }^{4}$

The current study showed that high cynicism, low professional efficacy and overall high burnout were reported more among students with low GPAs $(\leq 2.00$ out of 4.00). However, the number of study participants in the lowest GPA categories was relatively small, and the confidence intervals included one.

The results of the multivariate logistic regression analysis revealed that students whose GPA ranged between 3.51-4.00 were less prone to burnout as opposed to those whose GPAs were $\leq 2.00$ out of 4.00 . This finding was demonstrated in a Saudi Arabian study which reported that students with GPAs $<4.5$ out of 5.0 had higher burnout rates ( $\mathrm{n}=73,70.9 \%$ ) compared to students with GPAs $\geq 4.5$ ( $\mathrm{n}=88,62.9 \%)^{4}$ However, further studies are needed to investigate this issue.

Although the current study will add to the Saudi Arabian literature on burnout syndrome and may help in the early detection of burnout syndrome and the adoption of preventive measures, it has some important limitations. First, the cross-sectional design of this study determines statistical associations but not causal relationships. Second, the utilisation of a self-administered questionnaire could be a source of information bias. Finally, the study was carried out only in one location and thus was not representative of all Saudi medical students' burnout levels. Furthermore, given the low response rate, some cases with higher levels of burnout were potentially missed thus impacting the generalisability of the results.

Numerous strategies are required to decrease the burden of burnout among medical students, including involving students in extracurricular activities, altering educational and clinical environments to reduce avoidable stressors, providing good social support and engaging students in community service. ${ }^{22,23}$ Finally, longitudinal studies which follow medical students starting from college admission and ending at their graduation are warranted to explore potential burnout patterns. 


\section{Conclusion}

Burnout was found to be prevalent among medical students at Hail University, Saudi Arabia. Students with high GPAs were found to be less prone, however, to burnout syndrome. As burnout impacts the academic performance of medical students, further exploration of this problem and potential factors to reduce its burden should be of paramount importance to future researchers and medical educators.

\section{ACKNOWLEDGEMENT}

The authors gratefully acknowledge Mohammed Altriefi, Abdulrhman Alluhaybi and Talal Banan who assisted in the data collection for this paper.

\section{AVAILABILITY OF DATA AND MATERIALS}

Data used to support the findings of this study are available from the corresponding author upon request.

\section{CONFLICT OF INTEREST}

The authors declare no conflicts of interest.

\section{FUNDING}

No funding was received for this study.

\section{STROBE GUIDELINES}

This manuscript adheres to STROBE guidelines.

\section{References}

1. Rotenstein LS, Torre M, Ramos MA, Rosales RC, Guille C, Sen S, et al. Prevalence of burnout among physicians: A systematic review. JAMA 2018; 320:1131-50. https://doi.org/10.1001/ jama.2018.12777.

2. Kim MH, Mazenga AC, Simon K, Yu X, Ahmed S, Nyasulu P, et al. Burnout and self-reported suboptimal patient care amongst health care workers providing HIV care in Malawi. PLoS One 2018; 13:e0192983. https://doi.org/10.1371/journal.pone.0192983.

3. Mazurkiewicz R, Korenstein D, Fallar R, Ripp J. The prevalence and correlations of medical student burnout in the pre-clinical years: A cross-sectional study. Psychol Health Med 2012; 17:188-95. https://doi.org/10.1080/13548506.2011.597770.

4. Almalki SA, Almojali AI, Alothman AS, Masuadi EM, Alaqeel MK. Burnout and its association with extracurricular activities among medical students in Saudi Arabia. Int J Med Educ 2017; 8:144-50. https://doi.org/10.5116/ijme.58e3.ca8a.

5. Chang E, Eddins-Folensbee F, Coverdale J. Survey of the prevalence of burnout, stress, depression, and the use of supports by medical students at one school. Acad Psychiatry 2012; 36:177-82. https://doi.org/10.1176/appi.ap.11040079.

6. Costa EF, Santos SA, Santos AT, Melo EV, Andrade TM. Burnout syndrome and associated factors among medical students: A cross-sectional study. Clinics (Sao Paulo) 2012; 67:573-80. https://doi.org/10.6061/clinics/2012(06)05.
7. Dahlin ME, Runeson B. Burnout and psychiatric morbidity among medical students entering clinical training: A three year prospective questionnaire and interview-based study. BMC Med Educ 2007; 7:6. https://doi.org/10.1186/1472-6920-7-6

8. Dyrbye LN, Thomas MR, Massie FS, Power DV, Eacker A, Harper W, et al. Burnout and suicidal ideation among US medical students. J Annal Intern Med 2008; 149:334-41. https://doi.org/10.7326/0003-4819-149-5-200809020-00008.

9. El-Masry R, Ghreiz SM, Helal RM, Audeh AM, Shams T. Perceived stress and burnout among medical students during the clinical period of their education. Ibnosina J Med Biomed Sci 2013; 5:179-87. https://doi.org/10.4103/1947-489X.210543.

10. Al-Faris EA, Irfan F, Van der Vleuten CP, Naeem N, Alsalem A, Alamiri N, et al. The prevalence and correlates of depressive symptoms from an Arabian setting: A wake up call. Med Teach 2012; 34:S32-6. https://doi.org/10.3109/0142159X.2012.656755.

11. Muzafar Y, Khan HH, Ashraf H, Hussain W, Sajid H, Tahir M, et al. Burnout and its associated factors in medical students of Lahore, Pakistan. Cureus 2015; 7:e390. https://doi.org/10.7759/ cureus. 390 .

12. Youssef FF. Medical student stress, burnout and depression in Trinidad and Tobago. Acad Psychiatry 2016; 40:69-75. https:// doi.org/10.1007/s40596-015-0468-9.

13. Campos JA, Maroco J. [Maslach Burnout Inventory-Student Survey: Portugal-Brazil cross-cultural adaptation]. Rev Saude Publica 2012; 46:816-24. https://doi.org/10.1590/s0034-89102 012000500008

14. Ibrahim N, Al-Kharboush D, El-Khatib L, Al-Habib A, Asali D. Prevalence and predictors of anxiety and depression among female medical students in King Abdulaziz University, Jeddah, Saudi Arabia. Iran J Public Health 2013; 42:726-36.

15. Frajerman A, Morvan Y, Krebs MO, Gorwood P, Chaumette B. Burnout in medical students before residency: A systematic review and meta-analysis. Eur Psychiatry 2019; 36-42. https:// doi.org/10.1016/j.eurpsy.2018.08.006.

16. Schaufeli WB, Martinez IM, Pinto AM, Salanova M, Bakker AB. Burnout and engagement in university students: A cross-national study. J Cross-Cult Psychol 2002; 33:464-81. https://doi.org/10 $.1177 / 0022022102033005003$

17. $\mathrm{Hu} \mathrm{Q}$, Schaufeli WB. The factorial validity of the Maslach Burnout Inventory-Student Survey in China. Psychol Rep 2009; 105:394-408. https://doi.org/10.2466/PR0.105.2.394-408.

18. Tarnowski M, Carlotto MS. Burnout syndrome in students of psychology. Temas Psicol 2007; 15:173-80.

19. Altannir Y, Alnajjar W, Ahmad SO, Altannir M, Yousuf F, Obeidat A, et al. Assessment of burnout in medical undergraduate students in Riyadh, Saudi Arabia. BMC Med Educ 2019: 19;34. https:// doi.org/10.1186/s12909-019-1468-3

20. Galán F, Sanmartín A, Polo J, Giner L. Burnout risk in medical students in Spain using the Maslach Burnout Inventory-Student Survey. Int Arch Occup Environ Health 2011; 84:453-9. https://doi.org/10.1007/s00420-011-0623-x.

21. Chunming WM, Harrison R, MacIntyre R, Travaglia J, Balasooriya C. Burnout in medical students: A systematic review of experiences in Chinese medical schools. BMC Med Educ 2017; 17:217. https://doi.org/10.1186/s12909-017-1064-3.

22. Kim B, Jee S, Lee J, An S, Lee SM. Relationships between social support and student burnout: A meta-analytic approach. Stress Health 2018: 34;127-34. https://doi.org/10.1002/smi.2771.

23. Fontana MCP, Generoso IP, Sizilio A, Bivanco-Lima D. Burnout syndrome, extracurricular activities and social support among Brazilian internship medical students: A cross-sectional analysis. BMC Med Educ 2020; 20:81. https://doi.org/10.1186/s12909020-01998-6. 